\title{
The Effects of Horticultural Activity Based upon REBT Group Counseling on the Self-Expression and the Degree of Depression of the Female Marriage Immigrants'
}

\author{
Song Hee Park ${ }^{1}$ and Tae Yeol Jung ${ }^{2 *}$ \\ ${ }^{1}$ Department of Social Welfare Counseling, Koguryeo College, Naju 58280, South Korea \\ ${ }^{2}$ Department of Landscape Architecture, Kyungpook National University, Daegu 41566, South Korea
}

\begin{abstract}
This study was conducted to investigate the influences of a horticultural activity program applying REBT group counseling on female marriage immigrants' self-expression and the degree of depression. The subjects that applied for the program are 14 persons. With them, 10 sessions in total were carried out for two hours per time on every Wednesday at the J. gun (County) Social Welfare Center from December 17, 2013 through February 25, 2014. To look into a result of a pre-test on homogeneity between the control group and the experimental group. For self-expression as a result of a t-test in the control group, there was no significant difference in the average $(p=.825), \mathrm{t}=0.42(p>.05)$. For depression, in the control group, as a result of a t-test, there was no significant difference in the average $(p=.142), \mathrm{t}=-1.145(p>.05)$. To look into the change of self-expression according to the process the program. As a result of a T-test in the control group, there was a very significant decrease, $\mathrm{t}=-7.675(p<.001)$, it turned out that self-expression decreased during the program . As a result of a T-test in the experimental group there was a very significant increase, $\mathrm{t}=9.899(p<.001)$, it turned out that self-expression increased during the program. To look into the change of self-expression according to the process the program. To look into the change of depression. As a result of Wilcoxon signed-rank test in the control, there was a significant increase $(p=.016), \mathrm{z}=-2.410(p<.05)$, it turned out that their depression increased during the progress of the program. As a result of a T-test in the experimental group there was a very significant decrease, $t=-7.175(p<.001)$, it turned out that their depression decreased during the process of the program. As a result of a Pearson Correlation analysis on the factors of self-expression and factors of depression, their score of self-expression after the program had a significantly negative (-) correlation with their depression score ( $r=-0.705)$ after the program. Like the above results of the study, the horticultural activity applying REBT group counseling is effective for improving female marriage immigrants' self-expression and reducing their depression.
\end{abstract}

Key words: $A B C D E F$ principle, irrational belief, positive emotion, rational belief

\section{I . Introduction}

International marriage is a process combining all the different living environments of a married couple with different nationalities, such as culture, language and customs (So, 2009). Transition from one culture to another due to international marriage is not just a regional transition but a process that requires new thinking and behaviors (Lee, 2007), and not adjusting well may result in increased risk of facing mental health issues (Lee and Kang, 2007). Female marriage immigrants in the Korean society refer to women with foreign nationalities (Kim, 2014). They face diverse difficulties in the Korean society

Received on April 6, 2017. Revised on April 10, 2017.

Accepted on April 19, 2017.

*Comesponding author: jungty@knu.ac.kr such as social and cultural change (Byun, 2013), and many of them experience discrimination and prejudice, frustration and anxiety, hostility and alienation ( $\mathrm{Na}, 2008)$, which exposes them to an environment with high incidence of depression. Self-expression facilitates mutual communication and has a positive effect on human relations (Bae, 2012), and people with a high level of self-expression tend to show a low level of depression (Ramirez and Winer, 1983), whereas people that are not self-expressive show a high level of depression and maladjustment to human relations (Culkin and Perrotto, 1985).

Horticultural activity improved personal relations (Seok and Yoo, 2008) and mental health (Ha, 2011) for female marriage immigrants, improved marital relations (Kim et al., 2012), and reduced depression by helping cultural adjustment (Lee et al., 2010). As such, there are studies on horticultural 
activity for female marriage immigrants, but it is necessary to develop and supply more active programs for stable settlement of female marriage immigrants (Kim, 2007; Kim, 2011). Rational Emotive Behavior Therapy(REBT), formed based on the philosophy of Epictetus that "the ills humans suffer result from mistaken beliefs about what is truly good" (Park, 1997), does not prove that Activating Event (A) results in Consequence (C), but proves that Belief (B) about an individual's Activating Event (A) results in C, or emotional response, and that irrational belief leads to inappropriate emotions and behaviors, while rational belief leads to appropriate emotions and behaviors. Thus, REBT helps replace irrational belief with rational belief (Shin, 2000), and solves individual problems of the group members based on self-helping therapy (Seo and Kim, 2007) and cognitive, emotional and behavioral techniques. Lower irrational belief reduces depression (Shin and Won, 1991), and a horticultural therapy program applying REBT reduced elderly depression (Jung et al., 2010), improved self-esteem of middle school students not adjusting to school life (Yoon, 2010), and reduced depression of middle-aged women (Park and Jung, 2014). It is necessary to develop a horticultural activity program applying counseling to help female marriage immigrants adapt to home and social environment with emotional stability, but relevant research is insufficient with only about ten studies conducted. Thus, this study was conducted to determine the effects of horticultural activity applying REBT group counseling on self-expression and depression of female marriage immigrants.

\section{Research method}

\section{Research subject and period}

A horticultural activity program applying REBT group counseling was carried out to female marriage immigrants at the J. gun (County) Social Welfare Center (depression measurement result is 10 points or higher, 'depressed state'). The subjects of this study are 7 participants in the control group (average age 41.7; 3 from Mongolia, 2 from the Philippines, 2 from Japan; 6 high school graduates, 1 junior college graduate; average years of residence in Korea 14 years) and 7 participants in the experimental group (average age 41; 3 from Mongolia, 2 from the Philippines, 1 from Japan; 6 high school graduates,
1 junior college graduate, average years of residence in Korea 14 years) (Table 1). The research was conducted from December 17, 2013 to February 25, 2014, carrying out total 10 sessions (2 hours each) every Wednesday at the group counseling office. The group counseling leader who conducted the program (completed the group counseling expert course at the Korean Counseling Association, certified as Level 1 Horticultural Psychology Counselor by the Korea Association for University Continuing Education) received supervision of the group counseling training supervisor of the Korean Counseling Association every session.

\section{Program formation and process}

This study used the program of Park and Jung (2014) to improve self-expression and reduce depression of female marriage immigrants (Table 2). The horticultural activity program applying REBT group counseling consists of introduction, progress and conclusion. The introduction stage (Session 1) consisted of introducing one another and building intimacy. The cognitive aspect, which is the progress stage (Sessions 2 and 3), consisted of understanding depression situations, understanding oneself and recovering self-esteem

Table 1. Characteristics of the subjects before the horticultural activity applying Rational Emotive Behavior Therapy (REBT) group counseling.

\begin{tabular}{|c|c|c|c|}
\hline Item & Sub-item & Control group & Experimental group \\
\hline \multirow{3}{*}{ Age } & $30 \sim 39$ & 3 & 4 \\
\hline & $40 \sim 49$ & 4 & 3 \\
\hline & Total & 7 & 7 \\
\hline \multirow{4}{*}{ Nationality } & Mongolia & 3 & 3 \\
\hline & Philippines & 2 & 2 \\
\hline & Japan & 2 & 2 \\
\hline & Total & 7 & 7 \\
\hline \multirow{3}{*}{$\begin{array}{l}\text { Highest level } \\
\text { of education }\end{array}$} & High school & 6 & 6 \\
\hline & College & 1 & 1 \\
\hline & Total & 7 & 7 \\
\hline \multirow{3}{*}{$\begin{array}{l}\text { Year of } \\
\text { residence }\end{array}$} & $10 \sim 14$ & 4 & 4 \\
\hline & $15 \sim 19$ & 3 & 3 \\
\hline & Total & 7 & 7 \\
\hline \multirow{3}{*}{$\begin{array}{l}\text { No. of } \\
\text { Children }\end{array}$} & Over 2 & 7 & 5 \\
\hline & $0-1$ & 0 & 2 \\
\hline & Total & 7 & 7 \\
\hline
\end{tabular}


Table 2. REBT group counseling program utilizing horticultural activity (Park and Jung, 2014).

\begin{tabular}{|c|c|c|c|c|c|}
\hline \multirow{2}{*}{\multicolumn{2}{|c|}{ Stages }} & \multirow{2}{*}{ Session } & \multirow{2}{*}{ Subjects } & \multicolumn{2}{|c|}{ Contents } \\
\hline & & & & Rational Emotive Behavior Therapy & Horticultural Activity \\
\hline \multicolumn{2}{|c|}{ Pre-counselling } & \multicolumn{4}{|c|}{ Program introduction and Questionnaires for pre-assessment } \\
\hline \multicolumn{2}{|c|}{ Introduction } & 1 & $\begin{array}{l}\text { Self-introduction. } \\
\text { form intimacy }\end{array}$ & Let me introduce my depression & $\begin{array}{l}\text { Planting hope that you want to } \\
\text { bloom instead of depression }\end{array}$ \\
\hline \multirow{8}{*}{ Progress } & \multirow{3}{*}{$\begin{array}{l}\text { Cognitive } \\
\text { aspects }\end{array}$} & 2 & $\begin{array}{l}\text { Understanding depression } \\
\text { situations }\end{array}$ & $\begin{array}{c}\text { ABC principle;recognizing the } \\
\text { thought to the difference between } \\
\text { irB and } \mathrm{rB}\end{array}$ & $\begin{array}{l}\text { Planting rational beliefs that } \\
\text { I want to grow }\end{array}$ \\
\hline & & 3 & $\begin{array}{c}\text { Regain self-understanding and } \\
\text { self-esteem through depression } \\
\text { situations }\end{array}$ & $\begin{array}{l}\text { ABCDE principle; } \\
\text { changing irB to rB }\end{array}$ & $\begin{array}{l}\text { Giving flower basket } \\
\text { to important me }\end{array}$ \\
\hline & & 4 & $\begin{array}{l}\text { Recognizing the relationship } \\
\text { between incidents }\end{array}$ & $\begin{array}{c}\text { Disputing irB; } \\
\text { unconditional self-acceptanc }\end{array}$ & $\begin{array}{l}\text { Expressing the feeling of right now } \\
\text { in a cup flower arrangement }\end{array}$ \\
\hline & \multirow{3}{*}{$\begin{array}{l}\text { Emotional } \\
\text { aspects }\end{array}$} & 5 & $\begin{array}{l}\text { Understanding my feelings and } \\
\text { reactions }\end{array}$ & $\begin{array}{l}\mathrm{irB} \rightarrow \mathrm{irC} \rightarrow \mathrm{irE} \cdot \mathrm{irC} \rightarrow \mathrm{ir} \\
\text { Appropriate emotional changes }\end{array}$ & Making my flower topiary \\
\hline & & 6 & $\begin{array}{l}\text { Dealing with self-esteem by } \\
\text { improving positive emotions }\end{array}$ & $\begin{array}{c}\mathrm{E} \cdot \mathrm{F} / \text { understanding my emotions } \\
\text { understanding others } \\
\text { (inding depressoin patterns }\end{array}$ & $\begin{array}{l}\text { Making corsage that represents } \\
\text { my advantage }\end{array}$ \\
\hline & & 7 & $\begin{array}{l}\text { Dealing with depressions by } \\
\text { improving postive thinking and } \\
\text { emotions }\end{array}$ & $\begin{array}{l}\text { Applying ABCDEF principle· } \\
\text { How can I take care of myself? }\end{array}$ & $\begin{array}{l}\text { Taking care of myself through } \\
\text { healing garden }\end{array}$ \\
\hline & \multirow{2}{*}{$\begin{array}{l}\text { Behavioral } \\
\text { aspects }\end{array}$} & 8 & $\begin{array}{l}\text { Improving positive emotions } \\
\text { and change behaviors through } \\
\text { rational thought }\end{array}$ & $\begin{array}{l}\text { Applying ABCDEF principle } \\
\text { deal with depression }\end{array}$ & $\begin{array}{l}\text { Making my plants topiary with } \\
\text { decreased depression }\end{array}$ \\
\hline & & 9 & $\begin{array}{l}\text { Experiencing restoration of } \\
\text { self-esteem and decreased } \\
\text { depression by controlling } \\
\text { emotions }\end{array}$ & $\begin{array}{l}\text { Applying ABCDEF principle } \\
\text { deal with depression }\end{array}$ & $\begin{array}{l}\text { Continually washing away } \\
\text { elements interfering with the } \\
\text { recovery of depression by making } \\
\text { rose soap }\end{array}$ \\
\hline \multicolumn{2}{|c|}{ Conclusion } & 10 & $\begin{array}{l}\text { Congratulations and } \\
\text { encouragement on the changes } \\
\text { Post evaluation questionnaire }\end{array}$ & $\begin{array}{l}\text { Measuring the achievement of } \\
\text { objectives, conclusion }\end{array}$ & $\begin{array}{l}\text { Meeting changed myself while } \\
\text { infusing traditional tea }\end{array}$ \\
\hline
\end{tabular}

through depression situations, and perceiving relations with rational belief. The emotional aspect (Sessions 5 through 7) consisted of understanding one's feelings and responses, dealing with self-esteem by improving positive emotions, and dealing with depression by improving positive thinking and emotions. The behavioral aspect (Sessions 8 and 9) consisted of improving positive emotions and changing behaviors by changing rational belief, and recovering self-esteem and experiencing decreased depression with an affect regulation behavior. In the conclusion stage (Session 10), the subjects were congratulated and encouraged for their changes.

For the REBT group counseling technique, cognitive (capturing and disputing irrational belief), emotional (unconditional acceptance of subjects, self-disclosure of counselor), and behavioral (changing rational roles, self-expression training, using own language) techniques were used. Specific contents of the REBT group counseling consisted of introducing one's depression in Session 1, teaching the $\mathrm{ABC}$ principle and perceiving irrational and rational belief in Session 2, teaching the $\mathrm{ABCED}$ principle and changing irrational belief to rational belief in Session 3, disputing irrational belief and then accepting oneself as they are in Session 4, appropriately changing emotions through rational belief in Session 5, understanding the emotions of oneself and others with appropriate emotional change and then finding a depression pattern in Session 6, finding how to take care of oneself after applying the ABCEDF principle in Session 7, repeatedly handing depression by applying the ABCDEF principle in Sessions 8 and 9, and measuring the 
effects of goal attainment in Session 10.

The process of the horticultural activity consisted of the following steps. In the introduction stage (Session 1), the subjects introduced themselves and their depression in order to build intimacy and matched the process of a flower blooming and falling with their depression, by replanting Cyclamen persicum to a pot. They used their own language to express what they want to plant and bloom in their minds instead of depression, and the leader gave feedback. In Session 2, the progress stage, the subjects focused on the changes in thinking and understand their depression situations. Then, like a succulent plant that stores water in the fleshy leaves to adapt to the dry climate, the subjects replanted Echeveria peacockii 'Desmetiana' to a pot to plant rational belief in their mind to reduce their depression. After that, the leader gave feedback to the members on how the result of rational belief differs from that of irrational belief. In Session 3, the subjects made themselves flower baskets with Miniature Rose, Chrysanthemum frutescens $\mathrm{L}$ and Solidaster luteus to understand why they were forced to think irrationally and to recover their self-esteem. The leader gave feedback on how they perceived their situations with rational belief and how they expressed their feelings when giving themselves the flowers. In Session 4, the leader applied logical dispute (subjects 1,2,3,6), empirical dispute (subjects 4,5 ), and practical dispute (subject 7) for irrational belief of the subjects. After the leader's dispute, the subjects made flower arrangements in a cup with Eustoma grandiflorum shinn, Hylotelephium verticillatum and Rosa hybrida Hort. To depict their feelings 'here and now' in order to accept themselves as they are, after which the leader provided feedback during their self-expression. Session 5 was focused on emotional changes, and the subjects created flower topiary with Helianthus debilis Nutt, Diathus caryophyllus L, and Rosa hybrida Hort., and expressed their current feelings and responses after positive emotional change, for which the leader provided feedback. In Session 6, the subjects thought about their strengths in order to continuously improve positive emotions, and created corsages with five materials: Rosa hybrida Hort., Eustoma grandiflorum shinn, Limonium belidifolium (Gouan) Dumort, Gomphrena globosa, and Citrus limonium. The leader provided positive feedback on the strengths introduced by the subjects so that they could build self-esteem. In Session 7, the subjects created a garden of their current state of mind in the process of dealing with depression using Rosa hybrida Hort., Callistephus chinensis (L) Nees, and Aster Spp, and expressed how they can take care of the depression in the garden of their mind, for which the leader provided feedback. In Session 8, the subjects focused on behavioral changes and created plant topiary with Hedera helix, culture soil and artificial moss to express their state in which depression is controlled. The leader gave feedback on the changed positive emotions and behaviors of the subjects. In Session 9, the subjects made rose soap by putting dried rose leaves, Rosa Damascena oil, rose bath, base, glycerin and ethanol into rose molds to constantly wash off the obstacles for decrease of depression. The leader gave feedback on the recovered self-esteem of the subjects and the process in which their depression decreased. In Session 10, the conclusion stage, the subjects watched the way the flower of Chrysanthemum holds water and then blooms in the tea cup while brewing tea, and expressed how they feel about it and talked about the changes in their depression during the program. The leader congratulated them on their changes and provided encouraging feedback.

\section{Measurement tools}

\section{1) Self-expression scale}

For the self-expression scale, this study used the selfexpression rating scale made by Rakos and Schroeder (1980) and reorganized by Byeon and Kim (1980) according to the Korean cultural background. It is rated on a five-point scale, with higher scores indicating more desirable way of selfexpression. Reliability at the point of tool development was Cronbach $\boldsymbol{a}=.80$, and reliability in this study was Cronbach $\boldsymbol{a}=.86$.

\section{2) Depression scale}

Depression was measured with a self-report questionnaire developed by Beck (1967) to measure depression symptoms, and adapted by Lee and Song (1991). This scale consists of 21 items with the total score of 0-63 points, and 9 points or below is 'not depressed,' $10-15$ points is 'slightly depressed,' 16-23 points is 'somewhat depressed,' and 24-63 points is 'severely depressed.' Reliability at the point of tool development was 
Table 3. Nomality on independent t-test of self-expression and depression.

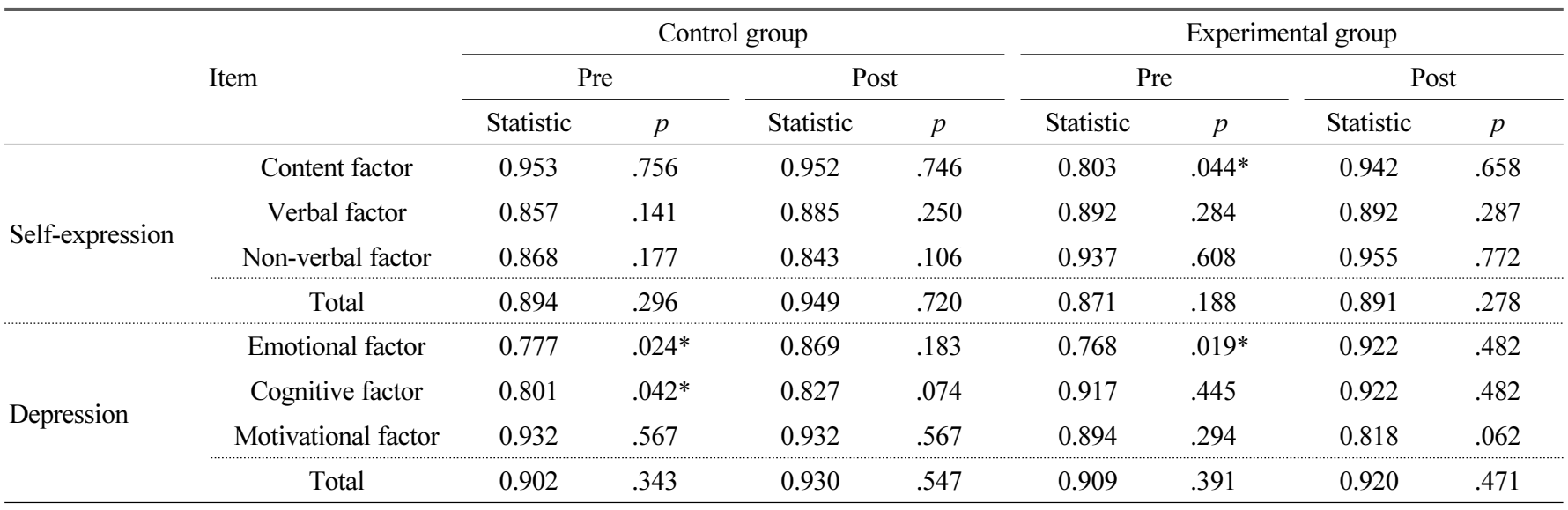

*Significant at $p<.05$ level by Shapiro-Wilks test.

Cronbach $\boldsymbol{a}=.86$, and reliability in this study was Cronbach $\boldsymbol{a}=.84$.

\section{Data analysis}

SPSS 21.0 was used for data analysis and reliability was verified with Cronbach $\boldsymbol{a}$ in the Measurement Tools section. For the homogeneity test between the two groups before implementing the program, the independent $t$-test was used when normality was fulfilled in both before and after the program, and the Mann-Whitney U-test (nonparametric method) was used when normality was not fulfilled. A paired t-test was conducted to analyze the significant difference in before and after implementing the program between the two groups. The non-parametric Wilcoxon signed rank test was applied when the distribution of the population did not fulfill normality, and the Spearman correlation analysis was conducted between self-expression and depression.

\section{Results and discussions}

\section{Test of normality}

1) Test of normality on independent t-test

Shapiro-Wilks statistics were verified to test normality, and normality was not satisfied in the content factor of the experimental group before the program in self-expression, whereas normality was not satisfied in the emotional and cognitive factor of the control group before the program in depression, and in the emotional factor of the experimental group before the program (Table 3 ).

2) Test of normality on paired-test

In the paired-test, Shapiro-Wilks statistics were verified to determine whether the difference between the two groups satisfies normality. Non-verbal factor did not satisfy normality in the experimental group for self-expression, and emotional factor and cognitive factor did not satisfy normality in the control group and the motivational factor did not satisfy normality in the experimental group for depression (Table 4).

Table 4. Nomality on paired-test of self-expression and depression.

\begin{tabular}{|c|c|c|c|c|c|}
\hline & \multirow{2}{*}{ Item } & \multicolumn{2}{|c|}{ Control group } & \multicolumn{2}{|c|}{ Experimental group } \\
\hline & & Statistic & $p$ & Statistic & $p$ \\
\hline \multirow{4}{*}{$\begin{array}{l}\text { Self- } \\
\text { expression }\end{array}$} & Content factor & 0.838 & .096 & 0.911 & .402 \\
\hline & Verbal factor & 0.922 & .482 & 0.844 & .107 \\
\hline & $\begin{array}{c}\text { Non-verbal } \\
\text { factor }\end{array}$ & 0.840 & .099 & 0.769 & $.020^{*}$ \\
\hline & Total & 0.920 & .471 & 0.826 & .073 \\
\hline \multirow{4}{*}{ Depression } & $\begin{array}{l}\text { Emotional } \\
\text { factor }\end{array}$ & 0.600 & $.000 * * *$ & 0.924 & .501 \\
\hline & $\begin{array}{l}\text { Cognitive } \\
\text { factor }\end{array}$ & 0.769 & $.020^{*}$ & 0.848 & .118 \\
\hline & $\begin{array}{l}\text { Motivational } \\
\text { factor }\end{array}$ & - & - & 0.719 & $.006 * *$ \\
\hline & Total & 0.773 & $.022 *$ & 0.915 & .429 \\
\hline
\end{tabular}

$*, * *, * * *$ Significant at $p<.05, .01, .001$ level by Shapiro-Wilks test. 
3) Equality of variance test on independent $t$-test

Equality of variance test is determining whether two groups have the same variance when conducting a t-test. Levene's equality of variance test was conducted only on items that satisfied normality and went through an independent t-test, and the cognitive factor of the experimental group did not satisfy equality of variance for depression (Table 5).

\section{Pretest on the homogeneity}

Table 6 shows the result of the pretest on the homogeneity between the control group and the experimental group. There was no significant difference in average, with the average score of the control group at 66.43 points and that of the experimental group at 68.14 points for self-expression $(p=.825)$. For depression, the average score of the control group was
13.43 points and that of the experimental group was 10.57 points, showing no significant difference $(p=.142)$. In other words, there was no difference in pretest scores between the control group and the experimental group.

\section{Changes in self-expression}

Table 7 shows the result of self-expression before and after the horticultural activity applying REBT group counseling. The control group showed a significant $(p<.001)$ decrease in the average score, with 66.43 points before the program and 61.29 points after the program, indicating that self-expression decreased during the program. The experimental group showed a highly significant $(p<.001)$ increase in the average score, with 68.14 points before the program and 74.57 points after the program, indicating that self-expression increased during the

Table 5. Equality of variance on independent-test of self-expression and depression.

\begin{tabular}{|c|c|c|c|c|c|}
\hline & \multirow{2}{*}{ Item } & \multicolumn{2}{|c|}{ Control group } & \multicolumn{2}{|c|}{ Experimental group } \\
\hline & & F-Statistic & $p$ & F-Statistic & $p$ \\
\hline \multirow{4}{*}{ Self-expression } & Content factor & 0.306 & .590 & - & - \\
\hline & Verbal factor & 0.005 & .946 & 0.190 & .670 \\
\hline & Non-verbal factor & 0.081 & .780 & 0.124 & .731 \\
\hline & Total & 0.313 & .586 & 0.218 & .649 \\
\hline \multirow{4}{*}{ Depression } & Emotional factor & - & - & - & - \\
\hline & Cognitive factor & - & - & 5.669 & $.035^{*}$ \\
\hline & Motivational factor & 0.000 & 1.000 & 0.019 & .893 \\
\hline & Total & 0.065 & .803 & 0.757 & .401 \\
\hline
\end{tabular}

*Significant at $p<.05$ level by Levene Equality of variance test.

Table 6. Pre-test on the homogeneity of self-expression and depression between the control group and the experimental group.

\begin{tabular}{|c|c|c|c|c|c|}
\hline & \multirow{2}{*}{ Item } & Control group & Experimental group & \multirow{2}{*}{$\mathrm{t}(\mathrm{z})$} & \multirow{2}{*}{$p$} \\
\hline & & $\mathrm{M} \pm \mathrm{SD}$ & $\mathrm{M} \pm \mathrm{SD}$ & & \\
\hline \multirow{4}{*}{ Self-expression } & Content factor & $31.00 \pm 4.830$ & $32.29 \pm 4.071$ & $-0.841 b$ & .441 \\
\hline & Verbal factor & $21.43 \pm 2.370$ & $20.14 \pm 4.140$ & -0.713 & .489 \\
\hline & Non-verbal factor & $14.00 \pm 1.826$ & $15.71 \pm 2.215$ & 1.580 & .140 \\
\hline & Total & $66.43 \pm 7.892$ & $68.14 \pm 7.381$ & 0.42 & .825 \\
\hline \multirow{4}{*}{ Depression } & Emotional factor & $5.14 \pm 1.864$ & $3.71 \pm 1.799$ & $-1.691 b$ & .113 \\
\hline & Cognitive factor & $5.57 \pm 3.101$ & $3.71 \pm 2.360$ & $-1.041 b$ & .323 \\
\hline & Motivational factor & $2.71 \pm 2.289$ & $3.14 \pm 1.069$ & 0.449 & .662 \\
\hline & Total & $13.43 \pm 6.106$ & $10.57 \pm 2.507$ & -1.145 & .142 \\
\hline
\end{tabular}

M: Mean, SD: Standard Deviation, b: Mann Whitney U test.

*Significant at $p<.05$ level by Independent t-test and Mann Whitney U test. 
Table 7. Results of self-expression before and after the horticultural activity applying REBT group counseling.

\begin{tabular}{|c|c|c|c|c|c|}
\hline \multirow{2}{*}{\multicolumn{2}{|c|}{ Self-expression }} & Pre & Post & \multirow{2}{*}{$\mathrm{t}(\mathrm{z})$} & \multirow{2}{*}{$p$} \\
\hline & & $\mathrm{M} \pm \mathrm{SD}$ & $\mathrm{M} \pm \mathrm{SD}$ & & \\
\hline \multirow{4}{*}{ Control group } & Content factor & $31.00 \pm 4.830$ & $28.00 \pm 4.865$ & -3.969 & $.007 * *$ \\
\hline & Verbal factor & $21.43 \pm 2.370$ & $20.14 \pm 2.673$ & -3.057 & $.022 *$ \\
\hline & Non-verbal factor & $14.00 \pm 1.826$ & $13.14 \pm 1.773$ & -3.286 & $.017^{*}$ \\
\hline & Total & $66.43 \pm 7.892$ & $61.29 \pm 7.296$ & -7.675 & $.000 * * *$ \\
\hline \multirow{4}{*}{ Experimental group } & Content factor & $32.29 \pm 4.071$ & $35.71 \pm 3.039$ & 4.563 & $.004 * *$ \\
\hline & Verbal factor & $20.14 \pm 4.140$ & $22.57 \pm 3.409$ & 4.250 & $.005^{* *}$ \\
\hline & Non-verbal factor & $15.71 \pm 2.215$ & $16.29 \pm 1.799$ & $-1.633 b$ & .250 \\
\hline & Total & $68.14 \pm 7.381$ & $74.57 \pm 6.852$ & 9.899 & $.000 * * *$ \\
\hline
\end{tabular}

M: Mean, SD: Standard Deviation, b: Wilcoxon signed-rank test.

$*, * *, * * *$ Significant at $p<.05, .01, .001$ level by Wilcoxon signed-rank test.

program. This result is consistent with the results of previous studies stating that horticultural activity has a positive effect on the emotional regulation ability and self-expression of children at community child centers (Woo et al., 2015), and that it is effective in improving self-expression of people with intellectual disability (Lee, 2011). Horticultural activity applying REBT group counseling switches irrational belief (irB) that affects depression situations (A: activating events) that are the main complaints of each of the members into rational belief (rB), helping reduce depression through positive emotions and behaviors (ABCDEF model is used), and horticultural activity is used as a medium in this process. The members expressed inappropriate emotions and behaviors ( $\mathrm{C}$ : consequence) they faced in different depression situations to other members and the leader and received feedback through the horticultural activities. After that, new philosophy (E: effect) is brought through dispute (D) and constant feedback, changing into appropriate emotions and behaviors (F: new feeling and behaviors), therefore improving self-expression. This is the difference from general horticultural activities. Irrational belief is what hinders self-expressive behaviors in the process of horticultural activities applying REBT group counseling (Ludwing and Lazarus, 1972; Lange and Jakubowski, 1980). Thus, the activities were carried out after the subjects find their own irrational belief and perceive the negative emotions and behaviors that affect their self-expression due to such irrational belief. The negative emotions felt by the members in the depression situations turned into positive emotions in the process of horticultural activities, and changes in self-expression due to the activities turned out to be diverse as follows. Subject 1 felt as if she were being reborn by breaking free from the mosseaten mind of constantly comparing herself to others as she watched the stems grow well from the topiary made with ivies. Subject 2 learned that a certain distance is needed between flowers as she arranged flowers in the basket, and realized that she needs to think in the other person's shoes without getting to close in her own way in conflicts. Subject 3 felt depressed as she watched Cvclamen persicum fall off in the pot, as it felt like her own family's sorrow. But as time passed, she felt that some things bloom while others fall, and realized how lovely the flowers were as she watered them. Subject 4 felt proud as she made the flower topiary and healing garden, thinking that her concealed self can actually do something well. Subject 5 discovered that watching the works she created with flowers and plants lit her up from depression, making her feel as if she wants to open up her heart to others as the flowers did to her. Subject 6 felt touched and overwhelmed when she put on the corsage she made on her chest, which made her feel as if she became someone special. Subject 7 felt empowered and encouraged as she raised Echeveria peacockii 'Desmetiana,' thinking that the flower will always be with her. The leader unconditionally accepted the subjects to express themselves 'here and now' in each session instead of expressing something of the past, and gave feedback so that they could reflect what they saw and felt, which may have improved self-expression of the subjects. 


\section{Changes in depression}

Table 8 shows the results of depression before and after the horticultural activity applying REBT group counseling. The control group showed a significant $(p=.016)$ increase in the average score, with 13.43 points before the program and 15.29 points after the program, indicating that depression increased during the program. The experimental group showed a highly significant $(p=.000)$ decrease in the average score, with 10.57 points before the program and 4.14 points after the program, indicating that depression decreased during the program. This result is consistent with the results of previous studies stating that the horticultural therapy program reduced depression of female marriage immigrants (Lee et al., 2010), that completed works of the horticultural therapy program applying REBT enabled the elderly to express irrational and negative thoughts to others and reduced their depression (Jung et al., 2010), and that REBT group counseling using horticultural activity reduced depression of middle-aged women (Park and Jung, 2014). In this study, the process in which the members found their depression patterns and changed in the process of horticultural activities applying REBT group counseling is as follows. Subject 1 said many ivy stems seem to be setting a direction for life for her, and seemed like her own self growing with a positive mind instead of comparing herself with others. Subject 2 felt that, when making eyes for the topiary, the ivy seemed to be looking her in the eye and felt alive, feeling like her own self relating to her daughter, with whom she had been in conflict before. Subject 3 said the topiary she created is lovely and the fresh ivy seemed like her own mind. Subject 4, as she made a mouth for the topiary, could understand why her mother-inlaw has to talk like that, and felt better about being able to say "yes." Subject 5 expressed satisfaction with the ivy stems that were just like herself wanting to bring joy instead of depression. Subject 6 was amazed by the new buds that kept growing from the ivy stems and wanted to value them because they looked like herself, developing little by little. Subject 7, when making the topiary, felt as if the artificial moss covering the ivy was covering herself as well, and expressed that the completed topiary was like herself recovered from depression. The leader focused on specific behaviors as well as changeable behaviors of the members participating in horticultural activities with various materials according to the theme of each session. Then the leader gave feedback, emphasizing that the situation itself does not cause depression, but that the irrational belief of individuals about the situation is what causes depression, and thus it is important to switch to rational belief. It seems that in the process of horticultural activities, the members could reduce their depression by encountering their changes into positive emotions and behaviors.

\section{Correlations between self-expression and depression}

Table 9 shows the results of correlation analysis among the factors of self-expression and depression. The self-expression score in the pretest had a significantly positive correlation with that in the posttest $(\mathrm{r}=0.775)$, and the depression score in the pretest had a significantly positive correlation with that in the

Table 8. Results of depression before and after the horticultural activity applying REBT group counseling.

\begin{tabular}{|c|c|c|c|c|c|}
\hline \multirow{2}{*}{\multicolumn{2}{|c|}{ Depression }} & Pre & Post & \multirow{2}{*}{$t(z)$} & \multirow{2}{*}{$p$} \\
\hline & & $\mathrm{M} \pm \mathrm{SD}$ & $\mathrm{M} \pm \mathrm{SD}$ & & \\
\hline \multirow{4}{*}{ Control group } & Emotional factor & $9.14 \pm 1.864$ & $9.43 \pm 1.902$ & $-1.414 b$ & .500 \\
\hline & Cognitive factor & $11.57 \pm 3.101$ & $12.14 \pm 2.853$ & $-1.633 b$ & .250 \\
\hline & Motivational factor & $5.71 \pm 2.289$ & $6.71 \pm 2.289$ & $-2.646 b$ & $.016^{*}$ \\
\hline & Total & $13.43 \pm 6.106$ & $15.29 \pm 5.707$ & $-2.410 b$ & $.016^{*}$ \\
\hline \multirow{4}{*}{ Experimental group } & Emotional factor & $7.71 \pm 1.799$ & $5.29 \pm 1.113$ & -4.250 & $.005 * *$ \\
\hline & Cognitive factor & $9.71 \pm 2.360$ & $7.71 \pm 1.113$ & -3.240 & $.018^{*}$ \\
\hline & Motivational factor & $6.14 \pm 1.069$ & $4.14 \pm 0.900$ & $-2.401 b$ & $.016^{*}$ \\
\hline & Total & $10.57 \pm 2.507$ & $4.14 \pm 1.773$ & -7.175 & $.000^{* * *}$ \\
\hline
\end{tabular}

M: Mean, SD: Standard Deviation, b: Wilcoxon signed-rank test

$*, * *, * * *$ Significant at $p<.05, .01, .001$ level by Wilcoxon signed-rank test. 
Table 9. Correlations among the main variables of self-expression and depression.

\begin{tabular}{|c|c|c|c|c|c|}
\hline \multirow{2}{*}{\multicolumn{2}{|c|}{ Classification }} & \multicolumn{2}{|c|}{ Pre } & \multicolumn{2}{|c|}{ Post } \\
\hline & & $\begin{array}{c}\text { Self- } \\
\text { expression }\end{array}$ & $\begin{array}{l}\text { Depress- } \\
\text { ion }\end{array}$ & $\begin{array}{c}\text { Self- } \\
\text { expression }\end{array}$ & $\begin{array}{c}\text { Depress- } \\
\text { ion }\end{array}$ \\
\hline \multirow{4}{*}{ Pre } & Self- & 1 & -0.362 & 0.775 & -0.355 \\
\hline & expression & & $(0.190)$ & $\left(0.001^{* *}\right)$ & $(0.213)$ \\
\hline & Donroccio & & 1 & -0.323 & 0.571 \\
\hline & 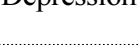 & & & $(0.260)$ & $\left(0.033^{*}\right)$ \\
\hline \multirow{3}{*}{ Post } & Self- & & & 1 & -0.705 \\
\hline & expression & & & & $\left(0.005^{* *}\right)$ \\
\hline & Depression & & & & 1 \\
\hline
\end{tabular}

Figures in brackets: significance level. figures out brackets: correlation coefficient.

**significant at $p<.01$ level by Spearman Correlation analysis.

posttest $(\mathrm{r}=0.571)$. However, the self-expression score in the posttest had a significantly negative correlation with the depression score in the posttest $(\mathrm{r}=-0.705)$. This result implies that subjects showing high self-expression scores after the horticultural activity program applying REBT group counseling showed low depression scores.

\section{Conclusion}

This study was conducted to determine the effects of the horticultural activity program applying REBT group counseling on self-expression and depression, by carrying out the program once a week from December 17, 2013 to February 25, 2014 with 7 subjects in the control group and 7 subjects in the experimental group with at least a slight level of depression among female marriage immigrants (who have lived in Korea for at least 10 years) using J. gun (County) Social Welfare Center. The results of the pretest on homogeneity between the control group and the experimental group showed that there was no significant difference between self-expression and depression, confirming that the two groups are homogenous.

Changes in self-expression due to the horticultural activity program applying REBT group counseling showed that the control group had lower self-expression with decreased average, whereas the experimental group had higher self-expression with increased average. Changes in depression showed that the control group had higher depression with increased average, whereas the experimental group had lower depression with decreased average. The results of analyzing the correlation between self-expression and depression showed that the selfexpression scores of the posttest had a significantly negative correlation with the depression scores $(\mathrm{r}=0.705)$, which indicates that subjects showing high self-expression scores after the horticultural activity program applying REBT group counseling showed low depression scores.

After the subjects switched to rational belief from irrational belief that made them feel depressed, self-expression increased in the horticultural activities of the theme in each session, and depression decreased in the process of sharing feedback. These results suggest that horticultural activity applying REBT group counseling is effective in improving self-expression and reducing depression of female marriage immigrants.

\section{References}

Bae, A.D. 2012. The effects of communication-oriented group art therapy on the self-expression and the degree of marriage satisfaction of international marriage migrant women. MS thesis, Seoul University of Buddhism., Seoul, Korea.

Byun, S.H. 2013. A case study on life and expectation of international Marriage Migrant women. MS thesis, Catholic Univ., Daegu, Korea.

Byeon, C.J. and S.H. Kim. 1980. Assertiveness Training Program. Student life research institute of Kyungpook Univ., Daegu, Korea.

Culkin, J. and R.S. Perrotto. 1985. Assertiveness factors and depression in a sample of college woman. Psycholog. Rep. 57:1015-1020.

Ha, Y.J. 2011. Effect of horticultural therapy program on acculturative stress and mental health in the internationally married female migrant. PhD Diss., Chonnam Natl. Univ., Gwangju, Korea.

Jung, H.Y., E.S. Lee, and Y.K. Yoo. 2010. Effects of Horticultural therapy on the Depression and Self-esteem in Old Woman of Day-care Center. J. Korean Soc. People Plants Environ. 13(6): 53-61.

Kim, G.H. 2007. A study on the education program helping immigrant females through international. MS thesis, Korea Natl. Univ. of Education, Seoul, Korea.

Kim, J.H., S.Y. Yun, and B.J. Choi. 2012. Effects of Horticultural Activity on the social adaptation and conjugal relationship of marriage immigrant feminine. J. Korean Soc. People Plants Environ. 15(2):67-71.

Kim, N.S. 2014. Phenomenological study om immigrant wives experience of adaptation process. MS thesis, Soongsil Univ., Seoul, Korea.

Kim, Y.H. 2011. The effects of group sandplay therapy on social 
anxiety, loneliness, and self- expression of international marriage immigrant women. MS thesis, Namseoul Univ., Seoul, Korea.

Lange, A.I. and P. Jakubowski. 1980. Responsible assertive behavior : Cognitive behavioral procedures for trainers. IL: Research press.

Lee, M.J. 2011. Effects of Horticultural Therapy on social skill and self-expression of the intellectually challenged people. J. Korean Soc. People Plants Environ. 14(4):199-205.

Lee, M.Y. and K.J. Kang. 2007. Effects a reality therapy group program for improving the self-esteem and marriage satisfaction of migrant women. Korean J. Fam. Welf. 12(2):29-44.

Lee, S.J., S.M. Lee, and J.K. Choi. 2010. Effects of horticultural therapy on the acculturation stress and depression of the internationally married migrant women. J. Korean Soc. People Plants Environ. 13(4):15-22.

Lee, Y.H. 2007. A study on Acculturative stress among The vietnamese Marriage Migrant women in Korea. MS thesis, Kangnam Univ., Changwon, Korea.

Lee, Y.H. and J.H. Song. 1991 A study of the reliability and the validity of the BDI, SDS and MMPI-D scales. Korean J. Clin. Psychol. 10(1):98-113.

Na, L.S. 2008. Affecting factors on the stress among foreign immigrant women by marriage in Korea. Korean Assoc. Nonprofit Organ. Res. 7(1):97-136.

Park, K.E. 1997. Rational Emotive Behavior Therapy. Hakjisa, Seoul, Korea.

Park, S.H. and T.Y. Jung. 2014. The effect of REBT group counseling utilizing horticultural activity on self-esteem and depression in middle-aged women. J. Korean Soc. People Plants Environ. 17(5):309-318.

Ramirez, J. and J.L. Winer. 1983. Counselor assertiveness and therapcutic effectveness in treating depression. Personnal Guid. J. 62:167-170.

Seo, S.K. and Y.H. Kim. 2007. Rational Emotive Behavior Therapy. Hakjisa, Seoul, Korea.

Seok, C.W. and Y.K. Yoo. 2008 Effect of the Horticultural Activity on Interpersonal Relationship in Woman Immigrant Married with Korean Man. J. Korean Soc. People Plants Environ. 11(3):91-98.

Shin, H.K. and H.T. Won. 1991. The comparative study of depressive group and anxious group in irrational beliefs and attributional style. Korean J. Clin. Psychol. 10(1):269-285.

Shin, H.R. 2000. The effect of REBT group counseling program on the Depression of middle school students. MS thesis, Han-Kook Univ., Seoul, Korea.

So, R.M. 2009. A study on situation of Migrant women's rights and laws and instituutions in Korea. Chosun Law J. 16(2):43-74.

Woo, M.R., S.Y. Yun and B.J. Choi. 2015. Effects of Horticultural activity on the emotional regulation ability and self-expression of children in community child center. J. Korean Soc. People Plants Environ. 18(5):437- 440.

Yoon, H.S. 2010. Effect of Horticultural Therapy based upon REBT group counseling on the Improvement of Self-Esteem and Reduction of Impulsivity in Maladjusted Middle School Students. MS thesis, Konkuk Univ., Seoul, Korea. 